\title{
CONTEXTUALIZANDO O TRABALHO DO JURISTA ESPANHOL JUAN DE SOLÁRZANO PEREIRA
}

\begin{abstract}
ÂNGELA BALLONE
RESUMO: O trabalho do Jurista espanhol Juan de Solárzano Pereira está conectado ao desenvolvimento do então chamado Derecho Indiano. Como alguém cuja vida se desenvolveu em contextos ligados aos dois lados do Atlântico, ele é uma figura complexa e muitas pesquisas a seu respeito precisam ser feitas. Este trabalho visa mostrar uma nova, consistente e atualizada análise da produção desse jurista em termos de trabalhos impressos. Por sua vez, isso pode ser de grande ajuda para contextualizar devidamente sua doutrina do Derecho Indiano, algo que dificilmente seria possível se focássemos apenas na versão espanhola - mais condensada - dos seus tratados em latim. Para meIhor entender os principais aspectos internos e arquitetura interna das concepções de Solórzano sobre o Derecho indiano, é importante estar ciente que seu trabalho tem sido originalmente projetado, transformado, e eventualmente circulado fora dos canais estritamente espanhóis. Estes desafios representam algumas dificuldades dependendo do corpo da bibliografia secundária disponível que, apesar de ampla, não oferece um estudo consistente sobre o autor. Olhando para sua produção como um sistema complexo dentro do qual cada livro cumpre um papel diferente, nós podemos não somente descobrir as próprias percepções do Solórzano a respeito do Derecho Indiano, mas também a agenda que a Coroa desejava defender veementemente apoiando-se em seu trabalho. Palavras-chave: Direito Indiano. Juan de Solórzano Pereira.Tomus Alter de Indiarum Iure.
\end{abstract}

\section{Contextualising the Work of the jurits Juan de Solórzano Pereira}

ABSTRACT: The work of the Spanish jurist Juan de Solórzano Pereira is linked to the development of the so-called Derecho indiano. As someone whose life developed in contexts linked to both sides of the Atlantic, he is a complex figure and one on which much research needs to be done. This work aims at providing a fresh, up to date and consistent, overview of this jurist's production in terms of printed works. In turn, this can be helpful to properly contextualise his doctrine of the Derecho indiano, something that is hardly possible if we focus just in the Spanish - more condensed - version his Latin treatises. In order to better grasp the main aspects and internal architecture of Solórzano's views on Derecho indiano, it is important to be aware of his work has been originally designed, changed and, eventually, circulated outside close Spanish channels. Such task encounters some difficulties depending on the corpus of secondary literature available which, albeit broad, does not offer a consistent study of this author's work. By looking at the latter as a complex system, within which each printed book fulfilled a different role, we can unveil not only Solórzano's own perceptions with regard to the Derecho indiano, but also the agenda that the Crown itself wished to defend by strenuously supporting his work.

Keywords: Derecho indiano. Juan de Solórzano Pereira. Tomus Alter de Indiarum lure.

\footnotetext{
${ }^{1}$ Doutora pela Universidade de Liverpool, Inglaterra. Pesquisadora do Max Planck Institute for Legal History, Alemanha. E-mail: angela.ballone@gmail.com
} 
A vida e o trabalho do jurista espanhol Juan de Solórzano Pereira (*1575, +1655) estão intrinsecamente ligados ao desenvolvimento do então chamado Derecho Indiano. ${ }^{2}$ Amplamente compreendido como um corpus de normas elaborado pela Coroa espanhola para administrar suas possessões transatlânticas, o desenvolvimento do que se tornou o Derecho Indiano um importante sujeito da história jurídica da América espanhola, progressivamente tomou uma posição que envolveu os dois lados do Atlântico. ${ }^{3}$ Tendo vivido aproximadamente vinte anos em Lima como um membro da Audiencia local, ${ }^{4}$ antes de se tornar um membro proeminente do Conselho das Índias em Madri, ${ }^{5}$ a vida de Solórzano estava profundamente interligada aos dois lados do Atlântico. ${ }^{6}$ Como comentário final, é importante destacar que Solórzano estava escrevendo durante o período da união das Coroas de Portugal e Espanha, um aspecto que precisa ser mais estudado no campo de pesquisa relacionado ao Derecho indiano. Mais uma vez, talvez seja especificamente através da comparação de textos escritos em latim e espanhol, que podemos melhor aproveitar a importância deste aspecto dentro da am-

\footnotetext{
${ }^{2}$ Em considerando os vários autores que escreveram tratados sobre as leis que a Espanha elaborou para as Américas, Antonio Muro Orejón dedicou uma particular ênfase em Solórzano. Para ele, "Hay muchos cultivadores de este apartado de la ciencia jurídica (...), y especialmente, por su magna obra, el Dr. Juan de Solórzano y Pereira. Éste, el más importante tratadista de derecho indiano, es siempre un indispensable y valioso elemento de consulta y su fama, que traspasa su vida, le lleva a ser citado como autoridad indiscutible en los distintos temas políticos, administrativos y jurídicos de las Indias;" (Muro Orejón, 1989, p. 143)

${ }^{3}$ Existem vários manuais sobre o Derecho Indiano disponíveis, apesar de estarem em espanhol. Para um estudo inicial, ver: (Dougnac Rodríguez, 1994). Disponível em:<http://www.colmich.edu.mx/rersab/ . Acesso em: 10/2017. Ver também (Ots Capdequí, 1945), particularmente as seções quatro e cinco; (Levaggi, 1991), em particular capítulo oito; (Pérez Fernández, 2001), além de todos os capítulos na publicação oficial do Código de Derecho indiano entre 1637 e 1681.

${ }^{4}$ A maior parte da bibliografia disponível sobre Solórzano está em espanhol. As únicas obras em inglês são as de James Muldoon, que conecta Solórzano a "era de ouro" do Império espanhol. De acordo com ele, esse jurista foi um "lawyer and an imperial officer". "Solórzano's career placed him in a unique position to observe the nature of the Spanish domain;" (Muldoon, 1999, p. 120-121). A despeito do longo período que passou em Lima, esse estudioso declarou que "when Solórzano came to write about the Spanish conquest and administration of the Americas he did so from the perspective of one who was there and who had participated in that work;" (Muldoon, 1992, p. 713). Além disso, ele identifica o trabalho de Solórzano como "significant for several reasons. It is neither the work of a priest who was an academic philosopher or theologian such as Francisco de Vitoria or Francisco Suárez, nor is it the work of a missionary such as Las Casas. Solórzano was a lawyer;" (Muldoon, 1998, p. 33).

${ }^{5} \mathrm{O}$ trabalho clássico sobre o Conselho das Índias permanece sendo o de Schäfer, principalmente o primeiro volume sobre a história do Conselho e as contribuições de Solórzano para ele; (Schäfer, 2003).

${ }^{6}$ Esse aspecto surge claramente nos estudos monográficos sobre o jurista, enquanto ele é descrito como "councillor of both [the old and the New] worlds" (García Hernán, 2007) ou como um autor capaz de "think the colony from the colony" (Bonnett Vélez e Castañeda, 2006). Para biografias de Solórzano, eu pessoalmente me fio do trabalho de (García Hernán, 2007), e (Barrios Pintado, 2013).
} 
pla comunidade de especialistas do direito no Atlântico ibérico. ${ }^{7}$ De forma gradual, no desenvolvimento do processo de construção do Derecho Indiano, a doutrina de Solórzano deve ser analisada como um processo diacrônico e não como um sistema definitivo (por exemplo como a elaborada para a Política Indiana).

Em seu tratado De Indiarum Iure - publicado em Madrid no ano de 1629 - ele

foi o primeiro a mencionar diretamente, ainda que em uma versão em latim, um específico conjunto de normas para as Índias, como as Américas eram referidas no períodos iniciais nos tempos modernos. ${ }^{8}$ Seu outro trabalho amplamente conhecido e citado é o tratado espanhol Política Indiana, ${ }^{9}$ o qual foi publicado em Madri em $1648 .{ }^{10}$ Até recentemente, este último foi o único trabalho facilmente acessível graças às muitas edições recentes feitas no século XX (em 1930, 1972 e 1996). ${ }^{11}$ Ao mesmo tempo, fre-

7 Nesse aspecto, é interessante observar como Solórzano aprofunda em detalhes quando discute a his-
tória dos descobrimentos portugueses no De Indiarum Iure, I.3, pp. 23-37, que corresponde a apenas
poucos parágrafos no final do primeiro capítulo de Política Indiana, I.1.10-12. Na introdução da última
edição e tradução do texto em latim, Jesús Bustamante García sumariza o terceiro capítulo De India-
rum lure como um "brief treatise about Western Indies and the Portuguese;" (Bustamante García, 2001, p. 25).

${ }^{8} \mathrm{O}$ título completo da obra é Disputationem de Indiarum Iure, sive de iusta Indiarum Occidentalium inquisitiones, acquisitione, et retentione tribus libris [daqui em diante De Indiarum lure]. A primeira edição está disponível em:<http://fondosdigitales.us.es/fondos/ z. Acesso em: 10/2017. Também disponível em acesso aberto estão outras edições desta obra. Referências para De Indiarum lure foram tiradas da primeira edição. Eu estarei usando numerais romanos para os livros e números ordinários tanto para os capítulos quanto para os parágrafos (por exemplo, III.8.1, para livro III, capítulo 8, e parágrafo 1). Grande quantidade de parágrafos será indicada coletivamente pelas páginas.

${ }^{9}$ Diferentemente dos tratados em latim, Solórzano não inclui o número dos parágrafos no tratado escrito em espanhol. Eles foram adicionados postumamente na reedição de 1736, organizada por Francisco Ramírez de Valenzuela (relator do Conselho das Índias). Para os propósitos deste artigo, e porque isso nos permite o mesmo sistema de referência utilizado para os tratado em latim, eu me referirei à última edição de Política indiana; (Tomás y Valiente e Barrero, 1996).

${ }^{10}$ Para a primeira edição deste tratado, ver http://www.bne.es (acesso 10-2017). Enquanto o frontispício (preparado pelo gravurista francês Robert Cordier) coloca como 1647 o ano da publicação, é mais provável que o trabalho foi publicado no ano seguinte. Isso aparece na segunda capa da Política indiana, onde um título mais extenso explica a sua conexão com o trabalho em latim de Solórzano. Para este aspecto, ver também (Hierro Anibarro, 2008, p. 63). Enquanto uma possível razão para isso talvez seja que a frente do fronstipício estava pronta antes do tratado. Deve ser notado que graficamente, o frontispício nas obras de Solórzano é basicamente o mesmo. Originalmente preparada pelo gravurista francês Robert Cordier para a primeira parte De Indiarum lure (na qual Filipe 4 estava na faixa dos vinte anos), o fronstípicio foi modificado em 1639, com um retrato mais adulto do rei, e reutilizado em todos os trabalhos posteriores. Sobre Cordier, ver (Blas, 2011).

${ }^{11}$ Como uma frequente confusão no acesso dessas edições, deve ser notado que não há diferenças substanciais entre elas. São todas baseadas no trabalho de Solórzano que foi revisado por Ramírez de Valenzuela na década de 1730 , quando os números dos diferentes parágrafos são basicamente os mesmos como apresentados nos índices de cada capítulo (muito na mesma linha de como Solórzano fez nos tratados escritos em latim). Deve ser observado que estranhamente há pontos de interrogação em alguns títulos de capítulos das edições do século. Presentes no tratado em latim, e em ambos os tratados espanhóis de Solórzano e aquele revisado por Ramírez de Valenzuela, esses pontos ortográficos foram removidos em todas as edições contemporâneas. Enquanto pode parecer um aspecto me- 
quentes referências ao tratado em latim e o papel de liderança de Solórzano no longo processo de preparação para a Recopilación de las Leyes de Indias tem sido unânime (Torre Revello, 1929a; Levaggi, 1991; Muro Orejón, 1989). Na maioria dos casos, pouco é mencionado a respeito da segunda parte do tratado em latim publicado em Madri em 1639, com o título Tomum Alterum de Indiarum lure (daqui em diante Tomus Alter). ${ }^{12}$ Mesmo quando se remete a sua censura pela Cúria Romana, um dos mais completos catálogos das várias censuras papais decretadas pela Congregação do Index refere-se primariamente ao De Indiarum lure, ao invés do Tomus Alter. ${ }^{13}$ Todavia, é com a publicação deste último que a Cúria Romana toma conhecimento do trabalho de Solórzano e o encara como algo perigoso e que precisa ser censurado. ${ }^{14}$ Algo parecido ocorria quando estudiosos se referiam a Solórzano e seus tratados jurídicos. ${ }^{15}$

Meu principal argumento é que se nós realmente queremos entender a doutrina de Derecho indiano de Solórzano, precisamos olhar para a totalidade de seu trabalho publicado. Portanto, o texto em Latim publicado em 1639 deve ser tão relevante

nor, minha argumentação é o fato de Solórzano ter usado pontos de interrogação pode ser indicativo de mais do que um processo de trabalho em andamento da definição de Derecho indiano, algo que os acadêmicos de história do direito deveriam ter em mente quando lidando com este tipo de tópicos hoje em dia. Apenas para dar um exemplo, ver "An illud servitii genus magis permittendum videatur, quod quidam ab Indis extorquent, quos vulgo Yanacnas vocant (...) contendunt?," in Tomus Alter, I.3, que torna-se "Del servicio personal de los indios que en el Perú llaman yanaconas, teniéndolos como por adscripticios y diputados para que labren y cultiven sus heredades sin permitirles se ausenten de ellas," in Política Indiana, II.4, mas perde os pontos de interrogação nas edições organizadas por Ots Capdequí and Tomás y Valiente (respectivamente in 1930 e 1996).

${ }^{12} \mathrm{O}$ título completo é Tomum Alterum de Indiarum lure, silve de Iusta Indiarum Occidentalum Gubernatione quinque libris [daqui em diante Tomus Alter]. Disponível em:<https://books.google.com/ $>$. Acesso em: 10/2017. Em relação a este trabalho usarei o mesmo sistema acima explicado para o De Indiarum lure.

${ }^{13}$ Consequentemente, Bujanda cita que o "Disputationem de Indiarum Jure (...) tribus libris (...) Madrid, F.co (Martínez, 1629), in-fol., 751, [100 p.], Madrid, BU, est interdit d'une façon absolue le 3éme libre di 20 tome concernant les questions ecclésiastiques et le patronato real; les autres libres du même ouvrage sont interdits en attendant d'être corriges. Donec corrig. Decr. 20-03-1642;" (Martínez de Bujanda, 2002, p. 844-845). Para um dos raros estudos sobre este caso de censura, ver (Leturia, 1948 e 1949).

${ }^{14}$ Analisei em detalhe esta censura e a documentação sobre isto está conservada no Arquivo para a Doutrina da Fé, em Roma, em (Ballone, 2018) (no prelo).

${ }^{15}$ Veja por exemplo, (Sánchez Maíllo, 2010, p. 60), onde não há nem mesmo o título completo do Tomus Alter, deixando uma referência lapidária de uma reação negativa proveniente da Cúria Romana. Além disso, nenhuma referência é feita a segunda parte do tratado em latim no resto do livro, que se baseia ao invés primariamente apenas na Política Indiana. O mesmo acontece em outro trabalho de compreensão sobre as ideias políticas de Solórzano, visto que as referências ao Tomus Alter são mínimas e os principais trabalhos tomam em consideração De Indiarum lure, o tratado espanhol e o livro dos emblemas (publicado em 1651); ver (Ayala, 1946). Finalmente, a fim de abranger todas as monografias que analisam Solórzano, também os que relacionam os aspectos econômicos da obra deste jurista permanece intimamente fechados a Política Indiana somente; ver por exemplo, a seção sobre o trabaIho indigena (discutido in Tomus Alter, I, e Política Indiana, II) em (Hierro Anibarro, 2008, p. 81-94). 
quanto a versão Espanhola "mais condensada" de $1648 .{ }^{16}$ Apesar de importantes publicações já terem lidado com ambos, Solórzano e o Derecho Indiano, a dispersão em diferentes repositórios e a dificuldade de recuperar alguns deles - a maior parte dos estudos clássicos estão esgotados - representam sérios problemas quando tentamos compreender as implicações mais amplas do papel desse jurista no desenvolvimento da complexa estrutura jurídica do Derecho Indiano. De todo modo, como veremos mais adiante, além da bibliografia disponível, muitos dos diversos trabalhos de Solórzano são de fácil acesso e podem ajudar nos estudos referentes a esse autor. Voltando ao exemplo do tratado jurídico em latim, é através dele que podemos compreender os caminhos pelos quais Solórzano combinou toda a literatura europeia disponível no início do século XVIII para lidar com o encontro transatlântico. Solórzano produziu um compreensível e consistente tratado, lidando com o panorama jurídico, tanto da Espanha quanto das Américas em uma perspectiva global mais ampla. Integrando as esferas normativas de ambos os lados do Atlântico, sublinhando práticas culturais com base nos princípios orientadores do Direito, religião e cultura europeias. Solórzano esteve focado em como se configuravam as interações sociais de ambos os contextos, caracterizadas por uma extrema diversidade. Portanto, o trabalho de Solórzano representa um excelente estudo de caso nos termos de uma abordagem multi-normativa do velho e do novo mundo. ${ }^{17}$

Olhando para estes tratados jurídicos de Solórzano como partes de um complexo sistema, no qual cada parte cumpre uma regra diferente, é possível revelar não somente como Solórzano os percebeu em sua própria mente, mas também a própria agenda que a Coroa estava defendendo quando se apoiou em seu trabalho contra todas as críticas (por exempo da Curia Romana). Recentemente descrito como "inevitável" para os estudos da história do Direito na América Ibérica, ${ }^{18}$ os autores clássicos

\footnotetext{
${ }^{16}$ Para abordagens semelhantes que indicam mais do que somente uma simples tradução do De Indiarum Iure/Tomus Alter para a Política Indiana, (GarcíaHernán, 2007, p. 178); (Ochoa Brun, 1972, p. 1364); (Barrios Pintado, 2013, p. 76-78).

${ }^{17}$ Baseado nas interações dos diferentes sistemas normativos que caracterizaram os espaços imperiais e os mundos coloniais modernos, a metodologia da multi-normatividade tem sido elaborada por Thomas Duve e representa o núcleo da metodologia em inúmeros projetos de pesquisa desenvolvidos no Max Planck Institute for European Legal History de Frankfurt (Alemanha). (Ver Duve, 2014, p. 12), e (Duve, 2016, p. 57-58).

${ }^{18}$ Apesar de Solórzano não estar no centro deste trabalho, José María García Marín efetivamente condensa as principais características das contribuições deste jurista para o desenvolvimento do Derecho indiano por meio do termo espanhol "inevitable"; (García Marín, 2011, p. 99).
} 
que lidam com o trabalho de Solórzano - no que diz respeito a comunidade acadêmica anglo-saxã - são Lewis Hanke e James Muldoon. Hanke se refere ao trabalho desse jurista como uma rica fonte para aqueles que se interessam pelos vários problemas teóricos do império (Hanke, 1949, p. 367). Curiosamente, esse estudioso foi inflexível ao pedir uma leitura mais consistente de todos os trabalhos de Solórzano, no seu conjunto. Segundo ele, para termos uma ideia mais clara do raciocínio teórico por trás da defesa da autoridade e governabilidade da Espanha sobre as Américas feitas por esse jurista, o texto em latim era muito mais relevante do que o escrito em espanhol. ${ }^{19} \mathrm{Di}$ ferentemente de Hanke, que esteve focado principalmente no século XVI, Muldoon foi além e considerou os problemas mais duradouros referentes às questões ainda não resolvidas sobre guerra justa, justos títulos e o tratamento das populações nativas das Américas naquele século. De acordo com Muldoon, "a questão do direito e do status dos habitantes do novo mundo continuaram nas discussões dos pensadores espanhóis" mesmo depois dos debates do século XVI, nos quais os principais adversários foram Las Casas e Sepúlveda (Muldoon, 1998, p. 31-32). Esse estudioso foi o único que destacou a popularidade de Solórzano no decorrer do início do século XIX e, curiosamente, entre os debates da Inglaterra e da América do Norte sobre a relação entre as colônias e sua metrópole. ${ }^{20}$ Ao mesmo tempo, enquanto o principal interesse de Muldoon aparenta ser no De Indiarum lure, o resto do tratado em latim parece desaparecer à medida que mais referências são feitas ao seu homólogo espanhol. De fato, o Tomus Alter desenvolve os caminhos pelos quais a América hispânica trabalhou de

\footnotetext{
${ }^{19}$ Conforme Hanke, o tratado em latim de Solórzano, para a qual ele se refere pelo título da primeira parte e os anos de publicação de ambas a primeira e a segunda parte (1629-1639), representada "un gran monumento de erudición jurídica e histórica." Além disso, ele destaca que "estos dos grandes volúmenes [em latin] son mucho más importantes para las cuestiones teóricas que la Política Indiana, del mismo autor, más conocidas, pero en la que se ha suprimido Buena parte de la discusión teórica;" (Hanke, 1949, p. 367).

${ }^{20}$ Muldoon refere-se a "several pamphlets dealing with the controversy between England and its North American colonies," todas citações do trabalho de Solórzano, como as de James Otis The Rights of the British Colonies asserted and Proved, incluído em Pamplets of the American Revolution, 1750-1776, citado em (Muldoon, 1998, p. 33). Além disso, Solórzano foi discutido também por Adam Smith no seu An Inquiry into the Nature and Causes of the Wealth of Nations (New York, 1937, 201), ou quando juristas norte-americanos debateram se ou não os Estados Unidos deveriam comprar a Flórida entre 1810 e 1818. Aparentemente, em 1833 muitas páginas do trabalho de Solórzano circularam dentro do Congresso dos Estados Unidos pelo representante da Flórida, Josehp M. White, que então depois publicou em uma coleção de material jurídico traduzida do espanhol para o inglês. Todos estes aspectos estão mencionados em (Muldoon, 1994, p. 9).
} 
forma prática através dos aspectos do governo. ${ }^{21}$ Este seria o último volume do tratado sobre o Derecho indiano, o que acabou preenchendo grande parte da Política Indiana. $^{22}$

A contribuição de Solórzano no período inicial da construção dos mundos modernos envolve uma ampla variedade de questões que foram cruciais na pauta da Coroa espanhola, todas as quais são perceptíveis em suas atividades como um autor e jurista a serviço da monarquia. Em seu trabalho, Solórzano constantemente se refere as suas experiências de ensinar e debater nas salas de aula da Universidade de Salamanca (onde ele estudou e ensinou de 1587 a 1609), também como sua longa e direta experiências nas Américas (de 1610 a 1626), ou seu trabalho como conselheiro das Índias no coração do Império espanhol (de 1627 até sua morte em 1655). Ele entra em grandes detalhes, provendo uma quantia esmagadora de informações e referências aos autores clássicos e contemporâneos, fontes históricas, religiosas e jurídicas. ${ }^{23}$ É importante que aqueles que pretendem entender sua doutrina a respeito do Derecho Indiano tenham em mente que a maior parte do aparato das fontes aparecem incompletas no Política Indiana, visto que as referências aos volumes do Latino são pouco perceptíveis, foram reorganizadas e encurtadas pelo próprio Solórzano no processo de preparação do manuscrito para impressão. Portanto, limitando os estudos do trabalho de Solórzano apenas ao tratado em espanhol, poderíamos perder uma grande parcela

\footnotetext{
${ }^{21}$ Eu discuto muito dos múltiplos aspectos ligado a Solórzano e o seu trabalho em (Ballone, 2018a), e (Ballone, 2018b). Ademais, posteriormente comecei a trabalhar num projeto mais amplo de comparação entre Tomus Alter e Política Indiana. Para a descrição deste projeto, ver http://www.rg.mpg.de/research/comparing-solorzano-from-within. Acesso em: 10/2017.

${ }^{22}$ Considerado em termos mais amplos, De Indiarum lure corresponde ao primeiro livro da Política Indiana, enquanto o Tomus Alter e seus cincos capítulos são consistentemente espelhados nos livros dois a seis do ultimo. Também deve ser notado que, enquanto o ultimo livro de Tomus Alter - sobre questões fiscais - é constituído por um único capítulo, na Politica Indiana nós temos uma discussão mais profunda do mesmo tópico em 17 capítulos.

${ }^{23}$ Nas palavras do historiador do direito Tomás y Valiente, "no hay jurista de la cultura del ius commune que no haya sido estudiado por Solórzano: los ha leído a todos. Pero no sólo de libros de derecho se componía aquella cultura y por eso no sólo los juristas aparecen citados por Solórzano. Hay teólogos (Agustín, Tomás de Aquino, Molina, Soto, Báñez), hay padres de la Iglesia (Ambrosio, Jerónimo, Clemente, Agustín), hay humanistas (Luis Vives, Erasmo, Tomás Moro, Alciato, Lorenzo Valla, Marsilio Ficino), hay clásicos latinos (Horacio, Ovidio, Virgilio, Séneca, Marcial), hay filósofos griegos (Platón, Aristóteles), hay «políticos» (como Maquiavelo, Bodino, Botero, Barclayo, o como Bobadilla y Gregorio López de Madera), hay tacitistas (como Justo Lipsio, Juan Sambuco), hay cronistas de Indias (Oviedo, Bernal Díaz del Castillo, López de Gómara) junto a indianistas de las más diversas especialidades como el padre Acosta, Matienzo, Agia, Torquemada, Antonio de León Pinelo, Fernando Pizarro, Las Casas, Antonio de Herrera y tantísimos otros que pueden incluirse en los grupos indicados o en otros varios o difícilmente clasificables;" (Tomás y Valiente, 1996, p. 28).
} 
de seu raciocínio lógico na construção dos principais argumentos por trás do Derecho Indiano.

\section{A Disputatio de Indiarum lure (1629)}

Concebido como um tratado em defesa dos títulos da Espanha para validar sua autoridade absoluta sobre as Américas, De Indiarum lure foi a primeira parte de um amplo projeto, no qual Solórzano pretendia oferecer uma análise dos aspectos práticos e legais do Direito espanhol sobre os novos e recentes territórios descobertos na América. ${ }^{24}$ Até o final do Século XX, esses documentos eram inacessíveis para aqueles que não conseguiam facilmente ler latim. Em 1990, essa obra foi objeto de estudo de um importante trabalho de crítica e tradução para o espanhol graças ao Consejo Superior de Investigaciones Científicas - CSIC. Sob a direção de Carlos Baciero, um grupo de estudiosos que trabalharam nos mais variados aspectos dos escritos e atividades de Solórzano, produziu uma indispensável tradução completa para o espanhol do De Indiarum lure. ${ }^{25}$ Mais especificamente, do ponto de vista da contribuição desse trabaIho para o campo de estudos da História do Direito, a tradução feita pelo CSIC apresenta alguns índices extremamente úteis. Lá, as fontes utilizadas por Solórzano são listadas com seus títulos completos, nomes dos autores e os anos de edição, o que contribui absurdamente para o processo de compreensão da doutrina desse jurista e sua base. Além disso, enquanto as referências utilizadas no Tomus Alter podem diferir daquelas do De Indiarum lure, e mesmo que elas não possam ser consideradas como uma bibliografia completa para este último, e certamente os índices feitos pelo CSIC representam uma ferramenta extremamente útil para navegação - com cautela - para o Tomus Alter também.

\footnotetext{
${ }^{24}$ Victor Tau Anzoátegui aponta uma coexistência das teorias legislativas e jurisprudencial no período moderno com relação a como as pessoas se apropriavam da ideia da Lei. Consequentemente, ele identifica os tratados de Solórzano como um projeto elaborado com vistas a este duplo aspecto, declarando a mesma abordagem - mais do que a escassez de recursos - deve ter estado entre as razões para o atraso da publicação do texto oficial das leis espanholas para as Américas a partir de $1680 \mathrm{com}$ a $R e$ copilación de Leyes de las Indias; (Tau Anzoátegui, 1996, p. 282).

${ }^{25}$ Começando a partir de 1994 e com base no terceiro livro de Indiarum lure, o Consejo Superior de Investigaciones Científicas tem gradativamente publicado todos os três livros incluídos na primeira parte do trabalho seminal de Solórzano dentro de sua série Corpus Hispaniorum de Pace, segunda serie. A obra inteira compreende quatro volumes, ao invés dos três livros originais de Solórzano, por causa do comprimento do Segundo livro (publicado em duas partes nos anos de 1999 e 2000).
} 
De Indiarum lure é estruturado em três livros (tribos libris comprehensum, como o título completo especifica). Ele segue as principais linhas de explicação dos diferentes processos de descoberta, conquista e conservação da América pela Espanha. O primeiro livro discute a importância das Américas do ponto de vista teológico e geográfico; nessa parte Solórzano oferece aos seus leitores uma análise do processo através do qual o conhecimento do Novo Mundo chegou a Europa, principalmente por vias Espanholas e Portuguesas. O segundo livro é o mais longo em todo o De Indiarum lure, e analisa os vários títulos, ou razões, sobre as quais a Espanha estabeleceu seu direito de conquistar o Novo Mundo. Essa parte em particular tem atraído a atenção dos estudiosos que analisam as percepções espanholas sobre a natureza dos Índios como bárbaros, infiéis e como povo devotado a práticas não naturais. ${ }^{26}$ Finalmente, 0 terceiro livro explica as razões pelas quais a Coroa Espanhola estava encarregada de governar as Américas. Esse livro foi o primeiro a ser traduzido pelo CSIC e está intrinsecamente relacionado ao debate acerca dos títulos justos da Espanha. Assim sendo, um número considerável de excelentes estudos introdutórios estão presentes nesse volu$\mathrm{me.}^{27}$

Publicado logo em seguida ao retorno de Solórzano a Espanha, o tratado De Indiarum lure representou um excelente meio para promover sua carreira até a Corte dos Habsburgo. Em particular, a publicação do longo trabalho sobre a descoberta, aquisição e conservação das Américas destacou a experiência do autor nesse campo, servindo assim como argumento base para que ele se tornasse um membro do ConseIho das índias, apesar da recente decisão de formalmente proibir a promoção de juízes americanos ao Conselho. Em fevereiro de 1628, Solórzano foi apontado como promotor no Conselho das Finanças. Aproximadamente no mesmo período, ele submeteu seu trabalho ao Conselho das Índias para obter a licença necessária para a publicação. Pouco depois disso, em junho de 1628, ele alcançou a nomeação que ele realmente

\footnotetext{
${ }^{26}$ Exemplos dos estudos sobre a natureza dos índios usando também a obra de Solórzano pode ser achado em (Muldoon, 1998, p. 35-42), (Muldoon, 1992, p. 713-719).

${ }^{27}$ Estes estudos discutem vários aspectos específicos do terceiro livro De Indiarum lure: Solórzano como um advogado trabalhando em defesa da Coroa (por Luciano Pereña); a base filosófica dessa defesa diante das críticas européias (por Carlos Baciero); uma visão geral das condições dos índios, a despeito do fato de que isso é o assunto do segundo livro De Indiarum lure (este ensaio foi feito por Jesús María García Añoveros); um estudo sobre a relação entre a Espanha e o papado sobre a base do direito medieval (por Antonio García y García); e finalmente, Francisco Cantelar Rodríguez analisa o Padroado real espanhol no terceiro livro do Tomus Alter. Para todos estes estudos, ver (Baciero, 1994).
} 
queria, se tornando procurador do Conselho das Índias. ${ }^{28}$ Promovido a conselheiro alguns meses depois, ele se tornou uma peça central na administração das Américas (para aquele conselho) e para a monarquia Espanhola (tendo um cargo também no Conselho de Castela) até sua morte, em 1655. Aparentemente, ele era extremamente orgulhoso da publicação do primeiro volume de seu tratado, até o ponto de escrever uma carta para o Papa Urbano VIII, Barberini, encaminhando a ele uma Cópia. ${ }^{29}$

\section{OTomus Alter de Indiarum lure (1639)}

A segunda parte do tratado foi publicada dez anos depois, com o título de Tomus Alter ${ }^{30}$ Juntos, os dois volumes em latim do primeiro tratado sobre o Derecho Indiano representam um vasto trabalho sobre as principais questões em jogo na descoberta das Américas: sua preservação com a Coroa Espanhola e a ampla comunidade cristã, e mais importante ainda, suas práticas administrativas. Em particular, o Tomus Alter propôs pela primeira vez uma precisa descrição das estruturas administrativas da América espanhola com profundas discussões sobre os pros e os contras de seus aspectos controversos (como por exemplo as normas sobre a liberdade dos índios ou o papel dos crioles com aqueles reinados). Devido a sua grande popularidade, Solórzano foi convidado a traduzi-lo para espanhol (Solórzano, 1648, “Al Rey”). O que deveria ser

\footnotetext{
${ }^{28}$ Em 1621 Filipe IV tinha começado o seu reinado, e em 1622 um dos estudantes de Solórzano alcançou a posição mais próxima do jovem rei, de valido. Com uma forte conexão pessoal do Olivares, e seu longo service em Lima, em junho de 1623 Solórzano reclamou amargamente para o valido sobre a recente decisão da Corte Imperial proibir a promoção das justiças da América para o Conselho das Índias. Ver Biblioteca Nacional de España, Ms. 9373, No. 17,198r-198v, publicados em (García Hernán, 2007, p. 328-329) Finalmente, Solórzano foi bem sucedido em ganhar o favor de Olivares, não somente retornando a Espanha no final de 1627, mas também ganhando um assento no conselho responsável pelos negócios na América española; (García Hernán, 2007, p. 179-181).

${ }^{29}$ Enquanto esta carta, ou a cópia dela, está conservada na Biblioteca Nacional da Espanha e foi publicada por Luciano Pereña como um apêndice documental em seu ensaio em (Baciero, 1994, p. 55), é difícil dizer se Solórzano efetivamente enviou este documento ou não. Na pesquisa nos arquivos e na Biblioteca do Estado do Vaticano, eu fui incapaz de achar algo relacionado ao fato de a Cúria ter recebido esta carta. Por outro lado, a Biblioteca do Vaticano possui varias cópias dos tratados de Solórzano em suas primeiras edições: quatro do De Indiarum lure, duas do Tomus Alter, uma da Política Indiana, um do Emblemata.

30 Largamente conhecida como De Gubernatione, eu me refiro a ela diferentemente - como um "outro tomo" - no sentido de fazer uma diferença marcante entre a primeira e a segunda parte do tratado. Frequentemente acadêmicos se referem ao tratado em latim de Solórzano utilizando-se do título da primeira parte. Enquanto isso não está incorreto, salvo quando os anos de publicação 1629-1639 - estão incluídos, isto talvez induza erroneamente o leitor que está tendo contato com seu trabalho pela primeira vez.
} 
considerado como uma tradução do Tomus Alter, o Política Indiana, ${ }^{31}$ foi publicado pela primeira vez em 1648 e então reimpresso inúmeras vezes nos anos posteriores. A maioria dessas edições modernas mais recentes está disponível na Internet e são de livre acesso no Google Books. De todo modo, esse não é o caso para as edições mais tardias do século $\mathrm{XX}$, que na maioria das vezes foram produzidas contemporaneamente a alguns dos mais recentes estudos inovadores sobre Solórzano e sua contribuição para o Derecho Indiano do ponto de vista jurídico na história moderna. ${ }^{32}$ Esses trabaIhos podem ser difíceis de serem encontrados, a menos que se tenha sorte o suficiente para ter acesso a uma biblioteca especializada em Derecho Indiano. ${ }^{33}$ Por outro lado, a maioria das bibliotecas universitárias com um interesse na América Colonial ocasionalmente tem a Politica Indiana em alguma de suas versões do século XX. ${ }^{34}$ Todas essas três edições apresentam esclarecedoras introduções aos estudos sobre Solórzano e seu trabalho no qual, em seu próprio tempo, representou uma importante contribuição para a historiografia. Todavia, eles contribuíram de alguma forma para percepções tendenciosas sobre o trabalho desse jurista, tanto que eles se referem muito pouco ao relacionamento entre o texto espanhol e o Tomus Alter.

Quase imediatamente após a publicação, este último atraiu a atenção da Con-

${ }^{31}$ Os dois trabalhos são frequentemente referidos como diferentes versões do mesmo tratado. Ver por exemplo (Dougnac Rodríguez, 1994, p. 15), em que esse autor afirma "la excelente síntesis sobre este nuevo derecho [el Derecho Indiano] que [se] publicó con el título de De De Indiarum lure (Madrid, 1629 e 1639), a que fue traducida al castellano como Política Indiana (Madrid, 1647)." Também Carlos Baciero apresenta a Política Indiana de uma forma enganosa quando afirma que o último representou uma "especie de adaptación o vulgarización, menos especializada científicamente"do tratado em latim; (Baciero, 2006, p. 264).

32 Um exemplo disto é (Torre Revello, 1929), um dos mais remotos estudos bibiliográficos sobre Solórzano e um realizado por um importante expoente no campo da história do direito das Américas. Deve ser ressaltado que desde as referências deste trabalho - junto com os seguintes do mesmo acadêmico (Torre Revello, 1933-34) - estão citados em recentes biografias (Barrios Pintado, 2013), deixando o leitor curioso sobre como ter acesso a tão extremamente rara publicação. Estes primeiros ensaios são importantes não somente porque focaram na vida do Solórzano (Torre Revello, 1929, p. 15-25), mas também porque proveram pela primeira vez uma lista compreensível de seus trabalhos (Torre Revello, 1929, p. 3-12) e, acima de tudo, um rico apêndice documental com transcrições de 11 documentos originais pelo Conselho das Índias endereçados a estes jurista (Torre Revello, 1929, p. 13-52).

${ }^{33}$ Este é o caso, por exemplo, da biblioteca do Max Planck Institute for European Legal History, no qual na última década embarcou numa série de projetos de pesquisa focando especificamente no campo da história do direito ibero-americano; Disponível em: <http://www.rg.mpg.de/research/legal_his tory_of_ibero_america $\geq$ Acesso em: 10/2017. Eu gostaria de agradecer a esta instituição por seu apoio na minha pesquisa sobre Solórzano.

${ }^{34}$ Estas edições são baseadas na edição do Valenzuela: que publicou em 1930 com uma introdução de José María Ots Capdequí, e sua edição fac-símile publicada pela Biblioteca de Autores Españoles em 1972 (mas com um estudo introdutório de Miguel Ángel Ochoa Brun). A última edição, seguindo o mesmo critério, é aquela publicada em 1996 e organizada pelos historiadores do direito Francisco Tomás y Valiente e Ana María Barrero. 
gregação do Index em Roma, para o seu tratamento do Padroado Régio sobre a Igreja Católica na América espanhola, e em 1641 foi censurado baseado nas análises negativas feitas por três especialistas daquela congregação, o Padre e ex-juiz da Collettoria da Espanha (ou Tesoureiro do Papa na Espanha) ${ }^{35}$ Antonio Lelio da Fermo, o dominicano Vincenzo Moreno e o jesuíta Melchor Inchofer ${ }^{36}$ Embora o De Indiarum lure não tenha sido o principal alvo da condenação, é importante notar que foi o segundo volume o único que causou a áspera condenação pela Cúria Romana, o mesmo que então ocuparia a parte principal da Politica Indiana. Publicada uma primeira vez em $1642,{ }^{37}$ a condenação foi reemitida no "Index librorum prohibitorum" de $1647 .{ }^{38}$ Enquanto a publicação da censura papal estava suspensa em todos os territórios sobre autoridade da Espanha, a "vulgarização e tradução" do tratado Latino (Baciero, 2006, 264) foi publicado pouco depois, em 1648. Ao passo que o De Indiarum lure sofreu um drástico redimensionamento para caber em um único livro - o primeiro do Política Indiana - o Tomus Alter tinha resultado em mais ou menos uma justa transposição de seus cinco livros em volumes do dois ao seis. ${ }^{39}$ A extensão da relação entre os volumes em latim e em espanhol continua esperando para ser apropriadamente avaliada pelos estudiosos, entre os quais a visão geral é dessa forma - o tratado-volume 2 - foi "simplesmente" traduzido pra o segundo - tratado-volume 1. No volume de 1000 páginas publicado em 1639, Solórzano incluiu referências aos trabalhos acadêmicos, assim como longas citações da documentação oficial, acesso garantido por privilégios obtido por compor o Conselho das Índias. Dos decretos reais para as instruções secretas aos

\footnotetext{
${ }^{35}$ Para um estudo do desenvolvimento deste tesouro papal e das tensões crescentes com a Coroa (apesar de focar no século XVI), ver (Carretero Zamora, 2013).

${ }^{36}$ Enquanto Lelio tem sido estudado em (Leturia, 1948 e 1949), uma versão panfletária deste relatório sobre o trabalho de Solórzano foi publicado em Roma em 1641, com o título de Observationes ad Tractatum de Indiarum iure lo annis de Solorzano Pereira. Cópias deste panfleto estão conservadas em Roma, Nápoles e Madri. O panfleto está disponível online (procurando por "Antonio Leli") em https://books.google.com/ . Acesso em: 10/2017. Inchofer é conhecido por seu papel no julgamento contra Galileu; (Beretta, 2005).

${ }^{37}$ Archivio Segreto Vaticano, Miscellanea, Armadio IV, vol. 30, Decretum Sacrae Congregationis ad Indicem Librorum (June 11, 1642).

${ }^{38}$ Biblioteca Casanatense, Per. Est. 18/7, n. 142, Decretum Sacrae Congregationis ad Indicem Librorum (December 18, 1646).

${ }^{39}$ Os dois trabalhos são frequentemente referidos como duas versões diferentes do mesmo tratado; conforme. A. Dougnac Rodríguez, Manual de Historia del Derecho Indiano, p. 15, na qual o autor declara "De Indiarum lure (Madrid, 1629 and 1639), la que fue traducida al castellano como Política Indiana (Madrid, 1647)." Entretanto, eu discordo desta teoria que não leva em consideração o fato de que, como um jurista, Solórzano, não cometeria o erro de desapreciar dessa forma o grande lapso de tempo do seu trabalho em latim (1629-1639) até o outro em espanhol (1647).
} 
vice-reis, para relatórios inéditos dirigidos ao rei da Espanha, a Política Indiana (como seu precursor o Tomus Alter) foi também desenvolvido para responder um número de questões sobre o caso americano circulando tanto na Corte quanto para além desta. A proliferação das exceções da América espanhola durante mais de um século, tornou-se unanimemente um problema, e um claro e consistente sistema de normas era necessário. A publicação dos tratados espanhóis de Solórzano tinha claramente o intuito de preencher precisamente essa lacuna.

\section{O Emblemata (1651)}

Em seus últimos anos, Solórzano publicou um livro com cem emblemas, o Emblemata Regio Politica (Madri, 1653), ${ }^{40}$ o qual é unanimemente considerado um dos principais trabalhos da literatura sobre emblemas (tanto quanto aqueles por Diego de Saavedra Fajardo). As imagens para os emblemas foram feitas pelo mesmo gravurista dos frontispícios dos tratados, Robert Cordier, que acompanhou o visual das ideias de Solórzano. ${ }^{41} \mathrm{~A}$ importância dos emblemas e de sua literatura no início dos tempos modernos é que tem sido estudada em diferentes pontos de vista. ${ }^{42}$ No estudo clássico do Mario Praz, focado no século XVII, ele refere-se brevemente a um dos emblemas de Solórzano (Praz, 1939, 13) para o interesse dos historiadores da arte como a Jesús Maria González Zárate, que analisa os emblemas do nosso jurista como um importante exemplo da cultura visual simbolizada pela cultura emblemática (González Zárate, 1987). O Emblemata constitui uma importante, e ao mesmo tempo, uma fonte pouco pesquisada para os estudos do início dos tempos modernos. Recentemente, um dos

\footnotetext{
${ }^{40}$ Título completo: Emblemata Regio Politica in centuriam unam redacta et laboriosis et que utilibus commentariis illustrate [daqui em diante Emblemata]. Disponível em: <https://archive.org $\geq$ Acesso em: 01-2017.

${ }^{41}$ De acordo com o acadêmico Jesús María González Zárate, Solórzano deu ao gravurista as indicações do que deveria ser feito em diversas imagens para o Emblemata; (González Zárate, 1987, p. 28). Quanto ao gravurista, embora tenha havido uma maioria de gravuristas flamengos que se mudaram para a Espanha nos séculos XVI e XVII, Cordier é um exemplo de gravuristas que se mudaram de lá para outros países europeus. Enquanto González Zárate nos conta que eles não desempenharam um papel na inovação de técnicas de gravuras, alguns deles aproveitaram longas carreiras. Robert Cordier esteve ativo entre as décadas de 1630 e 1660, e colaborou com a pintura de diversos trabalhos, como o frontispício da história de Madri de Gerónimo de Quintana, A la muy antigua, noble y coronada villa de Madrid: historia de su antiguedad, nobleza y grandeza (Madrid, 1629).

${ }^{42}$ Emblemas foram recentemente identificados como uma ferramenta útil para a compreensão dos aspectos visuais da lei, no que foi definido como uma "viragem visual" em estudos jurídicos; (Goodrich e Hayaert, 2015).
} 
emblemas de Solórzano tem sido discutido em detalhes no que diz respeito ao desenvolvimentos de novas ideias sobre o conhecimento no Atlântico ibérico (Brendecke, 2012, 52-64). Venerado pelos seus contemporâneos, o Emblemata circulou amplamente em diferentes tipos de traduções. Influenciado por Solórzano, ao menos dois autores trabalharam nas traduções de seus emblemas para o espanhol, aparentemente desconhecendo a existência de um e de outro (Selig, 1956, 283). Logo depois de sua publicação, os emblemas do Solórzano foram traduzidos pelo jurista valenciano Lorenzo Mateu i Sanz por pedido do sétimo duque de Montalto. ${ }^{43}$ Ao mesmo tempo, os emblemas de Solórzano desempenharam um importante papel no trabalho do jesuíta Andrés de Mendo, que estava entre aqueles que analisaram o trabalho antes da sua publicação e o deram uma licença formal para isso. ${ }^{44}$ Considerando que os emblemas de Solórzano são extremamente eruditos e importantes como uma fonte de boas práticas tanto para o príncipe quanto para seus ministros, Mendo publicou uma seleção de oitenta emblemas fora dos cem originais presentes no Emblemata. Os emblemas de Solórzano foram traduzidos também para o português em 1790, por Francisco Antonio Novaes Campos. ${ }^{45}$ Além disso, em 1816 Carlo Ludovico di Borbone-Parma, segundo Duque de Parma, dedicou a tradução dos emblemas do Mendo em italiano, para sua mãe, a Duquesa de Lucca. $^{46}$

\footnotetext{
${ }^{43}$ O Emblemas regio-politicos de don luan de Solorçano Pereyra (...) distribuidos en décadas (Valencia, 1658-1660) compreende não menos do que pequenos volumes impressos, embora também tenham circulado em manuscrito. Para as edições impressas, ver Biblioteca Nacional da Espanha, livros U/1187-1195, todos disponíveis online por meio da Biblioteca Digital Hispânica, em http://bdhrd.bne.es/. Acesso em: 10/2017. Para um exemplo da edição do manuscrito, ver Decada septima de los Emblemas de D. Iuan de Solorçano Pereyra (...) traducidos por el dotor Lorenco Mateu y Sanz, Biblioteca Universitária di Cagliari, Ms. A 5717.

${ }^{44} \mathrm{O}$ título completo da obra é Principe perfecto y ministros ajustados. Documentos politicos y morales en emblemas (Lyon, 1662), disponível online em:<https://archive.org/ $\geq$ Acesso em: 10/2017. Este não é o lugar para se discutir se Mendo plagiou os emblemas de Solórzano ou não. O que é relevante aqui é que a publicação próxima dessas duas obras, juntamente com a referência aberta do trabalho de Mendo ao Solórzano como inspiração, é indicativa da recepção do último. Para um estudo sobre Mendo, ver (Selig, 1956), e (Rey Sierra, 2000).

${ }^{45}$ Apesar do título ecoar os emblemas de Mendo, esta tradução apresenta todos os cem emblemas originalmente desenhados por Solórzano; ver Principe Perfeito. Emblemas de Dom Joaõ de Solorzano. Parafrazeados em sonetos portuguezes e offrecidos ao Serenissimo Senhor Dom Joaõ Principe do Brazil (1790), disponível online por meio da Biblioteca Nacional Digital do Brasil EM: $<$ http://bndigital.bn.gov.br/ $\geq$. Acesso em: 10/2017.

${ }^{46}$ Baseado na edição impressa em Lyon, em 1662, o título completo da obra é Il principe perfetto e ministri adattati. Documenti politici e morali corredati d'emblemi del Padre Andrea Mendo della compagnia di Gesú voltati dall'idioma castigliano (Rome, 1816), disponível online por meio de:<https://books.google.com/>. Acesso em: 10/2017.
} 


\section{A Política Indiana em uma Nova Perspectiva}

De acordo com as palavras do próprio Solórzano, quando ele estava escrevendo o tratado em espanhol, ele "no quise ni pude acomodarme a traducurlos letra por letra, así porque viniera a ser muy crecido y embarazoso el volumen, en tiempo, que esto solo basta para engendrar fastidio a los lectores (...) y por esta causa determiné no atarme tanto a la letra, como al intento [dos dois livros em latim], y mejorándole y añadiéndole en muchas partes, y abreviándole en otras, he sacado de ambos esta [obra], que intitulo Política Indiana, que comprende todo lo substancial de ellos [os dois livros em latim] en solo uno" (Solórzano, 1648. "Al Rey," 9). Contudo, o que ele obteve exatamente? Quais foram as razões em que ele se baseou na seleção de certas coisas substanciais em detrimento de outras coisas "menos" importantes? Até agora estes aspectos não foram considerados. Fazendo uma leitura um pouco mais severa dos textos, é possível fazermos algumas iniciais, entretanto temporárias, conclusões a este respeito. ${ }^{47}$ Inicialmente, quando olhamos para toda a produção impressa de Solórzano, o aspecto que claramente se destaca, é a Política Indiana, que é diferente de todos os outros trabalhos produzidos por este importante jurista sobre o Derecho Indiano. Enquanto esses são surpreendentemente precisos em seus mecanismos de crítica (uso de referências, citações diretas, longas discussões sobre estes), ${ }^{48}$ a Política Indiana é o único trabalho de Solórzano no qual encontramos uma pequena falta de precisão. Se nós considerarmos mais uma vez o contexto no qual foi publicado, enquanto a Espanha estava ocupada com esforços diplomáticos para convencer o Papa a remover a censura aplicada ao Tomus Alter, nós podemos nos perguntar se o último poderia estar ligado a alguma pressão sobre Solórzano para publicar seus tratados em espanhol apesar do fato de ele ainda estar trabalhando neles. ${ }^{49}$ Quando observamos as circunstâncias e a cronologia da censura papal, pode ser tentador pensar a publicação

\footnotetext{
${ }^{47}$ Isto é o argumento central por trás do meu projeto Comparing Solórzano from Within, que eu comecei a desenvolver no Max Planck Institute for European Legal History em 2017.

${ }^{48}$ Para além dos vários tratados, a coleção dos escritos de Solórzano publicada postumamente, em 1676, apresenta uma rica variedade de referências e citações diretas, discutidas com precisão pelo nosso autor; ver Solórzano, 1676, disponível online por meio da Biblioteca da Universidade Complutense de Madri, <http://biblioteca.ucm.es/ >.Acesso em: 10/2017.

${ }^{49}$ Para as trocas diplomáticas que ocorreram em Madri entre o núncio Giulio Rospigliosi (futuro papa Clemente IX) e os oficiais régios do Conselho das Índias, Castela e do Estado, Archivio Segreto Vaticano, Segreteria di Stato, Spagna, vol. 97, Di Madrid dal Mons. Nuntio (1647), 318v-328r. Para um estudo dessas negociações, (Leturia 1649, p. 80-82).
} 
da Política Indiana como um ultimato tomado pela Coroa para colocar um fim às reivindicações da Cúria de supervisionar a Igreja em ambos locais: Espanha e América espanhola.De todo modo, o único caminho para responder a essa pergunta reside em uma detalhada comparação entre os textos em latim e em espanhol - parte do meu atual projeto (ainda em fase inicial) - por hora, é o suficiente apontar para uma série de características que surgiram até agora. Portanto, vamos considerar três aspectos: $\mathrm{A}$ reformulação das referências de Solórzano (ou a falta disso), o tópico da barbárie dos índios, e uma específica passagem de ambos os tratados. ${ }^{50}$

Como um primeiro exemplo, nós já temos reparado em como a Política Indiana apresenta um pouco da ordem de reorganização das referências presentes no Tomus Alter. Apenas para ficar mais claro, outro exemplo: enquanto discutindo o valor dos preciosos metais no apoio as sociedades humanas no último tratado (I.13.43-47), Solórzano nos apresenta uma rica ordem de fontes e referências detalhadas dos trabaIhos de autores como o jesuíta espanhol Juan de Pineda e o jurista napolitano Camillo Borrello, o Bispo de Asti Simone Maiolo e o conferencista de direito Guido Panciroli (ambos italianos), o jesuíta Jules-César Bulanger e o jurista Étienne Forcadel (ambos franceses). Paradoxalmente, a passagem correspondente na Política Indiana (II.15.23) foi reduzida a algumas poucas linhas com todas as referências resumidas em uma única anotação. Referências no Tomus Alter são incluídas em versões mais curtas do que o título se refere, complementadas pelo número do livro, capítulo, parágrafo e o número da página. O mesmo não vale para a versão espanhola da mesma passagem, a Política Indiana apenas nos fornece os nomes dos autores e a referência do tratado em latim para as referências completas do trabalho deles. Outro aspecto que pode ser interessante para mais pesquisas, é a inconsistência no uso da língua espanhola e latina da Política Indiana. As anotações para o Tomus Alter tem sido simplesmente copiadas em latim junto com, em alguns casos, algumas novas em espanhol. ${ }^{49}$

Indo para o segundo aspecto, eu gostaria de discutir brevemente o tópico da barbárie dos índios que está intrinsecamente relacionado a razões para forçar eles a trabalharem contra sua vontade, e, para, além disso, funcionava também como um

\footnotetext{
${ }^{50}$ Veja por exemplo Política Indiana, "Al Rey," que é a tradução da dedicatória para Felipe IV da Espanha do Tomus Alter. Embora este aspecto tenha de ser confirmado no restante dos tratados, esta seção particular atinge a presença de 13 notas em espanhol, de um total de 61 em latim.
} 
mecanismo de educá-los para um modelo de civilidade europeia. ${ }^{51}$ Quando comparamos passagens nos textos em latim e nos espanhóis, nos quais Solórzano começa explicando o trabalho forçado dos índios, nós podemos encontrar uma referência direta ao seu barbarismo no Tomus Alter, I.1-2. Em contrapartida, na Política Indiana II.1-2, Solórzano destaca esse aspecto como ponto inicial de sua reflexão, afirmando que "porque a título del barbarismo, silvestre y fiero natural de las más naciones de estos indios fueron muchos de parecer que se les podía hacer guerra justa, y aun cazarlos, cautivarlos y domarlos como a salvajes, movidos por la doctrina de Aristóteles." Considerando essa curta passagem, um tanto quanto sugestiva, com esse exemplo poderia ser possível teorizar uma mudança gradual para pressionar a "natureza não civilizada dos índios" como forma de apoiar a guarda espanhola contra esses sujeitos livres. Mais uma vez, a resposta para essa hipótese está sobre uma leitura mais consistente de toda a produção do nosso jurista. Além disso, tal estudo deve expandir e permitir um entendimento mais profundo das principais teorias na corte espanhola em Madri, assim como as cortes do vice-rei no México e em Lima.

Indo para o nosso último exemplo, vamos considerar que um dos capítulos no qual Solórzano lida com o sério problema do trabalho forçado dos índios na extração de metais preciosos. Ele conhecia muito bem esse campo por que ele ficou por dois anos na cidade mineira de Huancavelica, como governador e inspetor. ${ }^{52}$ Quando discutindo as razões em favor do trabalho forçado nas minas, ${ }^{53}$ o rearranjo das passagens de Solórzano é interessante. Primeiramente, no tratado de 1639 , a presença do trabalho forçado entre os próprios Astecas e Incas se encaixa, em ambos os casos, nos exemplos da Roma antiga (Tomus Alter, I.13.49). Entretanto, no tratado de 1648 a mesma passagem é realocada para o fim do parágrafo, após mencionar o Imperador Frederick III (Política Indiana, II.15.28). ${ }^{54}$ Outra interessante mudança ocorre quando Solórzano

\footnotetext{
${ }^{51}$ Para o tratamento deste aspecto por Solórzano, ver (De Indiarum lure, II.8-9), e (Tomus Alter, I.1-5), no qual corresponde ao Política Indiana, I.9 e II.2-7.

52 Para um estudo deste período, (García Hernán, 2007, p. 139-149). As opiniões de Solórzano sobre essa experiência são relatadas em um documento que apresentou ao ocupar o cargo de procurador do Conselho das Índias; (Lohman Villena, 1950).

53 "De effossione et operatione metallorum, et an liceat Indos ad hoc laboriosum onus distribuere, et invitos fodinis, sive mineralibus mancipare? Relatis et illustratis argumentis quae pro affirmativa parte urgere videntur," (Tomus Alter, I.13.1-87).

54 O título completo do capítulo é "Del servicio de las minas y beneficio de sus metales, y si es lícito repartir para ellas Indios involuntarios? Se traen las razones y fundamentos que se suelen y pueden considerar en favor de la afirmativa."
} 
explica o porque os índios são forçados a trabalhar, ignorando seu sofrimento, por causa da utilidade que o trabalho deles tem para dar suporte ao reino. Aqui está toda a mudança na estrutura de argumentação. No Tomus Alter, I.13.65-70, Solórzano começa com uma metáfora do corpo humano, para mover para o exemplo do médico que é forçado a olhar para as pessoas doentes mesmo no meio de uma praga (o que poderia causar, por fim, sua própria morte) e então sobre o fato que genoveses e venezianos são forçados a lutar em tempos de guerra (até mesmo aqueles que podem acabar morrendo), para finalmente concluir com uma citação do genovês Pietro Andrea Canonieri, enquanto esse autor afirma que "mientras vive la cabeza, viven los demás miembros $^{\prime 55}$. Diferentemente dessa linha de pensamento, na Política Indiana, II.15.3133, Solórzano começa com o exemplo da república italiana, para ir rumo ao exemplo do médico e o corpo humano, concluiu com a citação do Canonieri. Talvez a lógica por trás dessa mudança resida no esforço de oferecer um raciocínio um pouco menos complexo, partindo de um exemplo mais geográfico (como esse da península italiana) para então concluir com uma citação direta que nos fornece em poucas palavras uma das principais razões usualmente oferecidas pelos pensadores espanhóis quando defendiam a necessidade de forçar os índios a trabalharem contra sua vontade.

\section{Conclusões}

Os esforços dos estudiosos em se envolver com a doutrina de Solórzano tem usualmente focado apenas no tratado espanhol deixando o escrito em latim de lado como uma simples referência. De fato, a presunção de proximidade entre ambos os textos, em latim e em espanhol, oferecem, tem aparecido em certo número de trabalhos lidando com ambos, este jurista e uma ampla compreensão do Derecho Indiano. Tal ideia talvez tenha nos levado a subestimar todo o processo de desenvolvimento e negociação do texto Latino ao redor do Derecho Indiano. Esta ideia contribui para os equívocos do papel do texto em latim o processo de desenvolvimento e negociação em torno do Derecho Indiano. Além disso, como discutimos anteriormente, a atual situação não depende essencialmente do conjunto de fontes disponíveis. Cronologicamen-

\footnotetext{
55 P.A. Canonieri, In septem Aphorismorum Hippocratis libros, Medicae, Politicae, Morales ac Thologicae, interpretationes (1617), citado tanto em (Tomus Alter, I.13.70), como (Política Indiana, II.15.33).
} 
te, o trabalho de Solórzano começou a ser amplamente citado e referenciado nos primeiros estágios de sua publicação (em 1629) para entrar no debate atual sobre o conceito do Derecho Indiano. Geograficamente, ele realizou suas atividades políticas e profissionais com um império global em uma era de complexos encontros com diferentes raças e "alteridade". Se por um lado, seu trabalho refere-se a regiões e continentes que por enquanto não são imediatamente identificáveis com a América Latina contemporânea (como as Filipinas), por outro, o papel central das experiências ibéricas na América tem tido uma importância significativa em como as pessoas de outros lugares da Europa tomam posição no início desse encontro global nos tempos modernos. 0 trabalho de Solórzano apresenta uma constante referência não apenas ao seu próprio tempo e espaço, mas também a uma ampla variedade de contextos e certamente, no momento atual. ${ }^{56}$ Estudiosos de inúmeros outros campos utilizam esse autor em seus questionamentos sobre o passado da América espanhola e desses mundos no Atlântico, assim como as configurações jurídicas, políticas e sociais de seu próprio tempo e espaço no século XXI. No contexto do início do moderno processo de definição do Derecho Indiano, Solórzano tem simbolizado isso em um caminho duradouro à medida que a popularidade de seu trabalho inegavelmente se destacava. Contudo, para se ter acesso a vida e o trabalho de Solórzano é necessário ter uma ideia clara do desenvolvimento de sua doutrina, que se destaca fortemente quando consideramos as conexões, diferenças e similaridades entre seus principais trabalhos em todo o Tomus Alter e o Política Indiana. Todavia, uma devida contextualização em termos de sua recepção e circulação, bem como as críticas recebidas de fora dos canais da monarquia espanhola, contribuem para o nosso conhecimento sobre Solórzano, do Derecho Indiano, e algumas das partes centrais dos aspectos do Atlântico ibérico. Enquanto não é possível discutir isso intensamente aqui através de uma profunda análise de todos esses aspectos, analisando ambas as produções desse jurista do período moderno e todo o processo contínuo de produção acadêmica sobre ele e seus tratados, e o estado da arte, este trabalho visou entregar aos especialistas e estudantes algumas indicações de como proceder diante das fontes secundárias e primárias sobre este importante jurista,

\footnotetext{
${ }^{56}$ De acordo com o acadêmico Santiago Hierro Anibarro, "esta visión global [de Solórzano] le convierte en una fuente ineludible para comprender las raíces de la economía iberoamericana;" (Hierro Anibarro, 2008, 22).
} 
oficial e especialista no Derecho Indiano.

\section{Referências}

AYALA, Francisco Javier de. 1946. Ideas políticas de Juan de Solórzano. Seville, Escuela de Estudios Hispano-Americanos, 583 p.

BACIERO, Carlos, et al. (eds.). 1994.Juan de Solórzano Pereira. De Indiarum lure (Libro III: De retentione Indiarum). Madrid, Consejo Superior de Investigaciones Científicas CSIC, $521 \mathrm{p}$.

BACIERO, Carlos, et al. (eds.). 1999.Juan de Solórzano Pereira. De Indiarum lure (Libro II: De acquisitione Indiarum, cap. 1-15). Madrid, Consejo Superior de Investigaciones Científicas - CSIC, 586 p.

BACIERO, Carlos, et al. (eds.). 2000.Juan de Solórzano Pereira. De Indiarum Iure (Libro II: De acquisitione Indiarum, cap. 16-25). Madrid, Consejo Superior de Investigaciones Científicas - CSIC, 561 p.

BACIERO, Carlos, et al. (eds.). 2001.Juan de Solórzano Pereira. De Indiarum lure (Libro I: De inquisitione Indiarum). Madrid, Consejo Superior de Investigaciones Científicas CSIC, $646 \mathrm{p}$.

BACIERO, Carlos. 2006. Juan de Solórzano Pereira y la defensa del indio en América.Hispania Sacra, Missionalia hispanica, 58(117): 263-327.

BALLONE, Angela. 2018. Contextualising the Papal Censure of the Disputationes de Indiarum Iure (1642). The Consultores of the Congregation of the Indes. Colonial Latin American Review, 2, forthcoming.

BALLONE, Angela. 2018b. Indians' Forced Labour as a Case for Exception in Seventeenth Century Colonial America. In: C. Ginzburg (ed.), A Historical Approach to Casuistry. Norms and Exceptions in a Comparative Perspective. Bloomsbury, forthcoming. BARRIOS PINTADO, Feliciano. 2013. SOLÓRZANO PEREIRA, Juan de. In AA.VV., Diccionario Biográfico Español. Madrid, Real Academia de la Historia, 47:76-78.

BERETTA, Francesco. 2005. Melchior Inchofer et l'hérésie de Galilée: censure doctrinale et hiérarchie intellectuelle. Journal of Modern European History, 3:23-49.

BLAS, Javier, Carlos; María Cruz de; Matilla, José Manuel. 2011. Grabadores extranjeros en la Corte española del Barroco. Madrid, Centro de Estudios Europa Hispánica, 746 p. 
BLAS, Javier. 2011. Grabadores extranjeros en la Corte española del Barroco. Madrid, Biblioteca Nacional de España - Centro de Estudios Europa Hispánica, 746 p.

BONNETT VÉLEZ, Diana; CASTAÑEDA, Felipe(eds.). 2006. Juan de Solórzano y Pereira. Pensar la Colonia desde la Colonia. Bogotá, Universidad de los Andes.

BORBONE-PARMA, Carlo Ludovico di. 1816. II principe perfetto e ministri adattati. Documenti politici e morali corredati d'emblemi del Padre Andrea Mendo della compagnia di Gesú voltati dall'idioma castigliano. Rome, Stampatore Vincenzo Poggioli, 472 p. Disponível em:<https://books.google.com/>. Acesso em: 10-2017.

BRENDECKE, Arendt. 2012. Imperio e información. Funciones del saber en el dominio colonial español. Madrid e Frankfurt, Iberoamericana Veruvert. 596p.

BUSTAMANTE GARCÍA, Jesús. 2001. Historia y ciencia para el derecho de una monarquía. In: C. BACIERO et al. (eds.), Juan de Solórzano Pereira. De Indiarum lure (Libro I: De inquisitione Indiarum). Madrid, Consejo Superior de Investigaciones Científicas CSIC, 17-37.

CARRETERO ZAMORA, Juan Manuel. 2013. La colectoría de España en el siglo XVI: los mecanismos de transferencia monetaria entre España y Roma (cambios y créditos). Hispania, 73(243):80-86.

DOUGNAC RODRíGUEZ, Antonio. 1994.Manual de Historia del Derecho Indiano. Mexico City, Universidad Nacional Autónoma de México, 456p.

DUVE, Thomas. 2014. European Legal History - Concepts, Methods, Challenges. In: T. DUVE (ed.), Entanglements in Legal History: Conceptual Approaches. Frankfurt, Max Planck Institute for European Legal History, Series Global Perspectives on Legal History, 29-66.Disponível em:<http://dx.doi.org/10.12946/gplh1>. Acesso em: 10-2017.

DUVE, Thomas. 2016. Global Legal History - A Methodological Approach. Duve, Thomas, Global Legal History - A Methodological Approach (April-May 2016). Max Planck Institute for European Legal History Research Paper Series, 2016-04, 1-22. Disponível em:<http://dx.doi.org/10.2139/ssrn.2781104 >. Acesso em: 10-2017.

GARCÍA HERNÁN, Enrique. 2007. Consejero de ambos mundo. Vida y obra de Juan de Solórzano Pereira (1575-1655). Madrid, Fundación Mapfre, 421 p.

GARCÍA MARÍN, José María. 2011. La justicia del Rey en Nueva España. Córdoba, Servicio de Publicaciones de la Universidad de Cordóba, 612 p.

GONZÁLEZ DE ZÁRATE, Jesús. 1987. Emblemas Regio-políticos de Juan de Solórza- 
no.Madrid, Ediciones Tuero, 232 p.

GONZÁLEZ ZARATE, Jesús María. 1987. Emblemas Regio-Políticos de Juan de Solórzano.Madrid, Ediciones Tuero, 232 p.

GOODRICH, Peter;HAYAERT, Valérie (eds.). 2015. Genealogies of Legal Vision. Oxford, Routledge, $279 \mathrm{p}$.

HANKE, Lewis. 1949. La lucha por la justicia en la conquista de América. Buenos Aires, Editorial Sudamericana, $572 \mathrm{p}$.

HIERRO ANIBARRO, Santiago. 2008. Economía y Derecho mercantil en la obra de Juan de Solórzano Pereira. Madrid, Marcial Pons, 271 p.

LELIO, Antonio. 1641b. Observationes ad Tractatum de Indiarum iure loannis de Solorzano Pereira. Rome, Typographia Reverendae Camerae Apostolicae. Disponível em:<https://books.google.com/>. Acesso em: 10-2017.

LETURIA, Pedro de. 1948. Antonio Lelio de Fermo y la condenación del 'De Indiarum lure' de Solórzano Pereira. Primera parte. Hispania Sacra, 1:351-385.

LETURIA, Pedro de. 1949. Antonio Lelio de Fermo y la condenación del 'De Indiarum lure' de Solórzano Pereira. Segunda parte. Hispania Sacra, 1:47-87.

LEVAGGI, Abelardo. 1991. Manual de Historia del Derecho Argentino (Castellano - Indiano/Nacional). Buenos Aires, Ediciones Depalma, 337p.

LOHMAN VILLENA, Guillermo. 1950. Un opúsculo desconocido de Solórzano Pereira sobre la mita. Anuario de Estudios Americano, 7:255-277.

MARTÍNEZ DE BUJANDA, Jesús. 2002. Index Librorum Prohibitorum, 1600-1966. Montréal, Centre d'Études de la Renaissance - Université de Sherbrooke, tomo XI, 979 p. MATEU I SANZ, Lorenzo. 1658-1660. Emblemas regio-politicos de don Iuan de Solorçano Pereyra (...) distribuidos en décadas. Valencia, Imprenta de Bernardo Nogues, 10 vols.Disponível em:<http://bdh-rd.bne.es/>. Acesso em: 10-2017.

MENDO, Andrés de. 1662. Principe perfecto y ministros ajustados. Documentos politicos y morales en emblemas. Lyon, Horacio Boissat y George Remeus. Disponível em:<https://archive.org/>.Acesso em: 10-2017.

MULDOON, James. 1992. The struggle for justice in the conquest of the New World. In S. CHODOROW (ed.), Proceedings of the Eighth International Congress of Medieval Canon Law. San diego, University of California at La Jolla, 21-27 August 1988. Città del Vaticano, Biblioteca Apostolica Vaticana, p. 707-720. 
MULDOON, James. 1994. The Americas in the Spanish World Order. The Justification for Conquest in the Seventeenth Century. Philadelphia, University of Pennsylvania Press, 239 p.

MULDOON, James. 1998. Solórzano's De indiarum iure: Applying a Medieval Theory of World Order in the Seventeenth Century. In: J. MULDOON (ed.), Canon Law, the Expansion of Europe, and World Order. Norfolk, Ashgate Variorum Collected Studies Series, VIII, p. 29-45.

MULDOON, James. 1999. Empire and Order. The Concept of Empire, 800-1800. Basingstoke, London, MacMillas Press, 209 p.

MURO OREJÓN, Antonio. 1989. Lecciones de historia del derecho hispano-indiano. Mexico City, Miguel Ángel Porrúa editor, 312 p.

NOVAES CAMPOS, Francisco Antonio de. 1790. Principe Perfeito. Emblemas de Dom Joaõ de Solorzano. Parafrazeados em sonetos portuguezes e offrecidos ao Serenissimo Senhor Dom Joaõ Principe do Brazil. 207 folios. Disponível em:<http://bndigital.bn. gov.br/>. Acesso em: 10-2017.

OCHOA BRUN, Miguel Ángel. 1972. Estudio preliminar. In: Política Indiana compuesta por el señor don Juan de Solórzano Pereira. In: AA.VV., Biblioteca de Autores Españoles, Madrid, Ediciones Atlas, 252:13-64.

OTS CAPDEQUÍ, José María. 1945. Manual de Historia del Derecho Español en las Indias y del Derecho propiamente Indiano. Buenos Aires, Editorial Losada, 499 p.

PÉREZ FERNÁNDEZ, Isacio. El Derecho Hispano-Indiano. Dinámica social de su proceso histórico constituyente. Salamanca, Editorial San Esteban, 608 p.

PILO GALLISAI, Rafaella. 2013. Three Engravers at the Service of a Sicilian Cardinal: De Noort, Villafranca, Clouwet and the Creation of an Unforgettable Political Portrait, 1644-1668. Ars Longa: Cuadernos de arte 22:163-164. Disponível em:<http://roderic.uv.es/handle/10550/28021>. Acesso em: 10-2017.

PRAZ, Mario. 1939. Studies in Seventeenth Century Imagery. London, Warburg Institute, $434 \mathrm{p}$.

REY SIERRA, Ana María. 2000. Mendo, a la sombra de Solórzano Pereira. In: S. LÓPEZ POZA (ed.), Estudios sobre literatura emblemática española. A Coruña, Sociedad de Cultura Valle Inclán, p. 261-271.

SÁNCHEZ MAÍlLO, Carmen. 2010. El pensamiento jurídico-político de Juan de Solórzano 
Pereira. Pamplona, Ediciones Universidad de Navarra, 296 p.

SCHÄFER, Ernesto. 2003. El Consejo real y supremo de las Indias: su historia, organización y labor administrativa hasta la terminación de la Casa de Austria [1935]. Madrid, Junta de Castilla y León, 2 vols.

SELIG, Karl-Ludwig. 1956. Concerning Solórzano Pereyra's Emblemata Regio-Politica and Andrés Mendo's Principe Perfecto. Modern Language Notes, 7:283-287.

SOLÓRZANO PEREIRA, Juan de. 1629. Disputationem de Indiarum lure, sive de iusta Indiarum Occidentalium inquisitiones, acquisitione, et retentione, tribus libris comprehensam. Madrid, Tipografía Francisco Martínez, 751 p. Disponível em:<http://fondosdigitales.us.es/fondos/>. Acesso em: 10-2017.

SOLÓRZANO PEREIRA, Juan de. 1639. Tomum alterum de Indiarum lure, sive de iusta Indiarum Occidentalium Gubernatione, quinque libris comprehensum.Madrid, Tipografía Francisco Martínez, 1076 p. Disponível em:<https://books.google.com/>. Acesso em: 10-2017.

SOLÓRZANO PEREIRA, Juan de. 1648. Política indiana. Madrid, Oficina de Diego Díaz de la Carrera, 1040 p. Disponível em:<http://www.bne.es>. Acesso em: 10-2017.

SOLÓRZANO PEREIRA, Juan de. 1651. Emblemata Centum, Regio Politica. Madrid, Tipografía Domingo García,844 p. Disponível em:<https://archive.org>. Acesso em: 102017.

SOLÓRZANO PEREIRA, Juan de. 1651.Obras varias, recopilación de diversos tratados, memoriales y papeles, escritos algunos en causas fiscales y llenos todos de mucha enseñanza y erudición.Zaragoza, Herederos de Diego Dormier,712 p. Disponível em:<http://biblioteca.ucm.es/>. Acesso em: 10-2017.

TAU ANZOÁTEGUI, Victor. 1996. Entre leyes, glosas y comentos. El episodio de la Recopilación de Indias. In:Homenaje al Profesor Alfonso García-Gallo. Madrid, Universidad Complutense, 3:266-283. Re-printed in V. TAU ANZOÁTEGUI, El jurista en el Nuevo Mundo. Pensamiento. Doctrina. Mentalidad. 2016. Berlin, Max Planck Institute for European Legal History, p. 147-166. Disponível em:<http://www.rg.mpg.de/publications/ global_perspectives_on_legal_history>.Acesso em: 10-2017.

TOMÁS Y VALIENTE, Francisco, and Ana María Barrero (eds.). 1996. Política Indiana por Juan de Solórzano. Madrid, Fundación Castro. 3 vols. 2989 p.

TOMÁS Y VALIENTE, Francisco. 1996. Introducción. In: F. TOMÁS Y VALIENTE; A.M 
BARRERO (eds.) Política Indiana por Juan de Solórzano. Madrid,Fundación Castro,p. 23-46.

TORRE REVELLO, José. 1929. Ensayo biográfico sobre Juan de Solórzano Pereira. Publicaciones del Instituto de Investigaciones Históricas, 44:15-25.

TORRE REVELLO, José. 1929a. Noticias históricas sobre la Recopilación de Indias. Buenos Aires, Imprenta de la Universidad, p. 15-28.

TORRE REVELLO, José. 1933-34. Juan de Solórzano Pereira. Nuevos datos para su biografía. Boletín del Instituto de Investigaciones Históricas de Buenos Aires, 17:1-29.

UREÑA, María Elena (eds.). 1985. Príncipe Perfeito. Emblemas de D. João de Solórzano [1790]. Lisboa, Instituto de Cultura e Lingua Portuguesa.

Artigo recebido em 30 de outubro de 2017 e aprovado em 05 de fevereiro de 2018. 